\title{
El intento de impresión de los \\ Comentarii sopra Cornelio Tacito \\ de Traiano Boccalini \\ en la corte española (1643-1652)
}

\author{
Sònia Boadas \\ Universitat Autònoma de Barcelona \\ sonia.boadas@gmail.com
}

Recepción: 01/05/2014, Aceptación: 29/05/2014, Publicación: 17/12/2014

\section{Resumen}

Con su repentina muerte en 1613, Traiano Boccalini dejó inéditos sus Comentarii sopra Cornelio Tacito, una obra que tardó más de medio siglo en aparecer en letras de molde. Durante este tiempo, los herederos del Lauretano intentaron publicar la herencia intelectual de su padre en las principales cortes europeas a cambio de algún beneficio económico. Gracias al descubrimiento de varios documentos inéditos, este artículo recompone el arduo y vano intento de publicación de los Comentarii por parte de su hijo, Aurelio Boccalini, bajo el auspicio de la corte española. La reconstrucción de este proceso pone de manifiesto las estrategias que se urdieron desde la corte madrileńa para evitar a toda costa la publicación de un texto que criticaba duramente la Monarquía española.

Palabras clave

Traiano Boccalini; Comentarii sopra Cornelio Tacito; Aurelio Boccalini; publicación

\begin{abstract}
The Attempt to print Boccalini's Comentarii sopra Cornelio Tácito at the Spanish Court (1643-1652)

Because of his sudden death in 1613, Traiano Boccalini left unpublished their Comentarii sopra Cornelio Tacito, a work that took more than half a century to appear in print. During this time, the heirs of the lauretano attempted to publish the intellectual inheritance from his father in the major European courts in exchange for some economic benefit. Thanks to the discovery of several previously unpublished documents, this article reconstructs the arduous and vain attempt to publish the Comentarii by his son, Aurelio Boccalini, under the auspices of the Spanish Court. The reconstruction of this process highlights the strate-
\end{abstract}


gies that are concocted from the Madrid Court to avoid at all costs the publication of a text that was harshly critical of the Spanish monarchy.

Keywords

Traiano Boccalini; Comentarii sopra Cornelio Tacito; Aurelio Boccalini; publication

\section{Los Comentarii en las principales cortes europeas}

Más de medio siglo separa la redacción de los Comentarii sopra Cornelio Tacito de Traiano Boccalini y su aparición en letras de molde. ${ }^{1}$ Durante gran parte de estos años algunas copias manuscritas del texto circularon por las principales cortes europeas de la mano de los hijos del Lauretano, que quisieron utilizar sagazmente la herencia intelectual de su padre como valiosa moneda de cambio para conseguir privilegios y sustanciales remuneraciones económicas. De esta manera, a lo largo de prácticamente todo el siglo xviI, el texto de los Comentarii boccaliniano se convirtió en un producto que se intentaba vender al mejor postor.

De entre todos los intentos, no hay duda de que el más conocido fue el que protagonizaron los descendientes del Lauretano en la República de Venecia. ${ }^{2}$ Catorce años después de la muerte de Traiano, en 1627, sus dos hijos varones, Rodolfo y Aurelio Boccalini, ofrecieron al Consiglio dei Dieci de la República de Venecia un manuscrito inédito de su padre con comentarios a las obras de Tácito para su impresión. ${ }^{3}$ Más allá de divulgar el legado literario de su progenitor, lo que realmente interesaba a los hermanos era conseguir una buena cuantía de dinero por la cesión del manuscrito. En ese sentido, y para conseguir el beneplácito de las autoridades de la República, los herederos autorizaron cualquier cambio o modificación del texto por parte del Consiglio. Fueron cuatro los

1. El presente trabajo se inscribe en el Proyecto de Investigación FFI2011-22929 («Diego de Saavedra Fajardo y las corrientes intelectuales y literarias del Humanismo») financiadopor el Ministerio de Ciencia e Innovación. Mi agradecimiento a Alessandro Martinengo y a Valentina Salmaso por sus indicaciones.

2. Véanse los trabajos de Hendrix (1995), Tirri (1998) y Gagliardi (2013).

3. Actualmente, este manuscrito se conserva en el Archivo de Estado veneciano, con signatura Consiglio dei Dieci, Miscellanea codici 104. Lo describen Cicogna (1834: IV, 356-359) y Tirri (1998: 480-482). Para la transcripción de los documentos que entregaron los hermanos Boccalini a la República y la respuesta del Consiglio dei Dieci véase Hendrix (1995: 270-279). 
expertos que evaluaron la publicación de los Comentarii y de forma unánime coincidieron en considerar inapropiada la publicación del texto por las duras críticas que contenían hacia la autoridad papal y la monarquía española, lo que se podría interpretar como un signo de aprobación por parte de la Serenísima. Sin embargo, a pesar de la negativa del Consiglio, los herederos consiguieron una compensación económica: a cambio de renunciar a la devolución del manuscrito y a la publicación de la obra - ya fuera en la República o en cualquier otro estado- recibieron una pensión vitalicia de doce ducados.

Es muy probable que esta resolución de la Serenísima sirviese de inspiración para los hermanos Boccalini, que vieron en la herencia de su padre una excelente fuente de ingresos económicos. Caso omiso hicieron de las condiciones pactadas con la República de Venecia, principalmente a partir de los años cuarenta, cuando fray Aurelio, ${ }^{4}$ único heredero del tesoro literario de su padre después de la muerte de sus dos hermanos, Rodolfo y Catalina, abanderó los intentos de publicación de los Comentarii sopra Cornelio Tacito en las principales cortes europeas. Fue a finales de la década de los Treinta cuando Aurelio Boccalini entró al servicio del rey de Polonia, Ladislao IV. Tal y como atestigua la carta del Nuncio de Varsovia, fray Aurelio ofreció al monarca el manuscrito original de la obra de su progenitor: ${ }^{5}$

Hora il Boccalini è qui in concetto d'haver ingegno, mà valersene in cose simili, con le quali vi s'è insinuato per mezzo del Puccitello suo corrispondente, il principio fu alcuni anni sono che mandò a Sua Maestà l'originale de' Commentari di Traiano suo padre sopra Tacito, di che pretese 6000 ungari, e n'ebbe solo il titolo di segretario e 200 scudi di provisione in Napoli, credo durante la sua vita. ${ }^{6}$

Una carta de presentación muy útil que le proporcionó una recompensa sustancial: el rey de Polonia le concedió una provisión de 200 escudos así como el título de secretario. Poco tiempo después, en 1640, fray Aurelio se estableció en Venecia como residente de Ladislao IV, donde se encargó de misiones diplomáticas y todo parece indicar que también actuaba como agente doble, informando a varios dirigentes europeos como fueron, por ejemplo, la duquesa de Saboya o el rey de Francia (Tirri, 1998: 468).

\section{Los Comentarii en la corte espańola 2.1. El inicio de las negociaciones}

Como bien señalaron Bouza (1995) y posteriormente Gagliardi (2013), ni la merecida fama de antiespañol que había acompañado el nombre de su padre

4. Véase la biografía de Aurelio Boccalini que ofrece Benzoni (1969, XI: 4-6).

5. Para la localización actual de dicho manuscrito y su fortuna a lo largo de los siglos, véase Tirri (1998: 467 y ss.).

6. Carta del Nuncio de Varsovia. 2 de noviembre de 1641. Citado por Tirri (1998: 471) 
ni las virulentas críticas a la monarquía española contenidas en los Comentarii impidieron que Aurelio Boccalini, en uno de sus intentos de publicar la obra y conseguir los réditos económicos convenientes, intentara imprimirla bajo el favor del rey Felipe IV. Según la documentación custodiada en el Archivo General de Simancas, las negociaciones para la publicación de la obra se remontan a mediados de noviembre de 1643, cuando Aurelio Boccalini habría ofrecido el legado intelectual de su padre al embajador español en Venecia, don Gaspar Tebes de Córdoba, marqués de la Fuente. ${ }^{7}$ A través de la siguiente misiva el Marqués informaba de los acontecimientos a la corte de Madrid:

Como ya he dado cuenta a V.Mag. el Abad Fray Aurelio Bocalino ha continuado el acudir a mi posada y yo el oírle con recato, así por haber él tenido pensión de Francia como por lo poco afecto que su padre fue a la corona de V.Mag., no dejándolo dudar lo que es tan posible y también lo manifiesta (según el juicio común) en un libro mano escrito que dejó y que ha días que trata de imprimir su hijo, obligado por juzgar la obra tan grande que servirá de laurel a las cenizas de su autor, como por creer que será tan aplaudida que consiga con publicarla una ayuda de costa muy considerable. Desde que este religioso me vino a buscar con carta del rey de Polonia, como en una mía de 28 de agosto di cuenta a V.M., procuré que con demostraciones acreditase la reconciliación que me proponía, y en esta sesión y en otras que después he tenido con él no declinaba a más que a remitirse a las experiencias que yo haría con el tiempo. Últimamente me propuso con ponderaciones de italiano sobre buen orador que me entregaría los tres cuerpos de que se compone este libro que intitulará Consideratione Politiche di Trayano Bocalini, para que leyéndole pudiese entresacar en lo que juzgasen que tenía inconveniente, porque aunque él había cancelado mucho no fiaba de su censura por la parte del poco conocimiento de las cosas, no por la de la voluntad con que estaba de agradar a V.M. y de borrar el crédito que dejó su padre. Estimele el afecto que mostraba, asegurándome que nunca se arrepentiría de las demostraciones que hiciese y después de muchas protestas de no apartar jamás ni su ánimo ni sus escritos del servicio de V.M. me aseguró que la primera parte la quería obrar estampándola debajo del nombre de V.M. y la segunda del rey de Polonia, su amo.

No admití el censurar yo esta obra ni me ajusté a que se estampare con mi consentimiento mientras de uno y otro no diese cuenta a V.M. Propúsele que sería bueno remitirla a Madrid para que V.M. la mandase ver. Representó la grande dilación del viaje y que le haría mucho mayor la calidad de las ocupaciones que estorbarían el determinar materia de este género, demás de que era casi imposible que se hiciese nada no siendo en parte donde él pudiese satisfacer muchas dudas que era fuerza ofrecerse. Estas que ponía procuré ver si se podrían suplir sirviéndose V.M de mandar remitir este negocio a ministro de Italia que fuese servido. No halló cómo vencer la falta que haría no asistir él a quien registrase esta obra ni el faltar de aquí,

7. Sin embargo, los contactos de fray Aurelio con el Marqués ya habrían empezado algunos años antes. Parece que en 1636 el duque de Parma encargó a Aurelio Boccalini y a Girolamo Brusoni que negociasen un acuerdo con España a través del embajador español en Venecia, el marqués de la Fuente (Benzoni, 1969, XI: 4-6; Tirri, 1998: 468). 
estando por orden del rey de Polonia. Yo le desahucié de que pudiese tener efecto lo que deseaba, pues al mismo tiempo que yo diese cuenta a V.M. le suplicaría (como lo hago) que no me mandase que yo solo entrase en esta materia.

Propúsome por medio término que yo podría leerlo y en las partes que hallase no solo que con claridad tocase a la corona de V.M. pero aun con palabras indirectas si no quisiese absorberlas o condenarlas por solo mi parecer, remitiese aquel o aquellos pliegos (pues no eran muchos) y al ministro o ministros que me pareciese, para que con su acuerdo se caminase sin escrúpulo, y ofrecí dar parte a V.M. de los buenos designios que mostraba y de las dudas que ponía para que resolviese lo que fuese servido. Y porque V.M. pueda mandar ver el asunto y la forma en que introduce hablar en todos los príncipes, me ha parecido remitirle los treinta y cinco pliegos inclusos. ${ }^{8}$ Desea mucho la brevedad en la resolución temiendo que su poca salud acorte su vida. He intentado persuadirle a que deje esta obra pues por ventura no hallará tanto aplauso como se promete, y él mostraba que sacrificaría su modo de entender y el interés que juzga sacar de publicarla si se tenía por servicio de V.M., pero dice que será mucho peor porque entre esta República y el Gran Duque tienen copia de casi toda la obra con que se estamparía sin esta revisión. ${ }^{9}$

Este documento pone de manifiesto que como mínimo desde mediados de agosto de 1643 Aurelio Boccalini había mantenido contacto con el Marqués para intentar gestionar la publicación de la obra de su progenitor en España. Sin embargo, el interés que suscita esta epístola va más allá de una simple fecha a quo porque desvela otros detalles hasta hoy desconocidos. Por una parte, vale la pena destacar el proceso de manipulación y distorsión del texto en manos del heredero, que había "cancelado mucho" de lo que consideró que podía desagradar al monarca español, así como su expresa aprobación para que se "pudiese entresacar en lo que juzgasen que tenía inconveniente», unas indicaciones que nos recuerdan muy de cerca a las que algunos años antes habían dado los hermanos Boccalini al Consiglio dei Dieci. ${ }^{10}$ Por otro lado, también es pertinente señalar los reparos de Aurelio en enviar el texto a Madrid, alegando la dilación que causaría el ir y venir de los documentos y el no poder supervisar en perso-

8. En el margen del documento aparece una nota manuscrita que indica que sólo se recibieron siete pliegos.

9. Regularizo la ortografía y la puntuación de los textos que se transcriben. Carta del marqués de la Fuente. Venecia, 13 de noviembre de 1643. Archivo General de Simancas (AGS), Secretaría de Estado (SE), Legajo 3543-15. Es posible que el Gran Duque fuera el Gran Duque de Toscana, Fernando II de Medici (1610-1670).

10. «Et perché nella serie di questi gravissimi discorsi vi sono inserte infinite massime di ragion di stato esplicate con moderni essempii di singolariss.i fatti et attioni operate da maggiori prencipi del mondo, et particolarm.te dall'antichissimo et ser.mo fermo governo di questa augustiss.a rep. $\mathrm{ca}$, è paruto convenevole ad ambedue noi fratelli, avanti che siino publicati al mondo, di presentarli a questo ecc.so tribunale, acciocché VV.EE. [...] possino farle vedere da chi più li piace aggiongere, o diminuire ove più fosse stimato a proposito". Carta de Rodolfo y Aurelio Boccalini al Consiglio dei Dieci. Cito por Hendrix (1995: 271). 
na la tarea de los censores españoles. Ante este inconveniente, el Consejo de Estado decidió que el marqués de la Fuente fuese el encargado de leer la obra y remitir a otro ministro aquellas partes que pudiesen perjudicar a la corte española. Siguiendo debidamente estas instrucciones, el Marqués decidió enviar a Madrid siete pliegos de los Comentarii boccalinianos para su valoración. La misiva termina con una referencia a Francia y al Gran Duque, quienes parecía que también disponían de copias de la obra del Lauretano. No hay duda de que la intención de fray Aurelio era evitar la dilación de las correcciones en la corte española, por lo que procuró que el Marqués informara debidamente que había otros dirigentes interesados en la publicación del texto.

\subsection{Las valoraciones de don Pedro de Neyla y del Consejo de Estado}

A principios de abril de 1644, el Consejo de Estado español juzgó lo que convenía hacer en esta cuestión, sugiriendo que algún ministro togado leyera y valorara los pliegos que se habían remitido para saber si era conveniente su publicación. Asimismo, se enviaron instrucciones al marqués de la Fuente para que quietara los ánimos de Aurelio Boccalini dándole una ayuda de costa de quinientos ducados por si quería desplazarse a Milán. ${ }^{11}$ En septiembre del mismo año, el marqués de la Fuente confirmaba haber recibido las disposiciones de la corte de Madrid y daba cuenta de cómo avanzaban los asuntos de Aurelio Boccalini. Por otra parte, desde España se había resuelto que el Gran Canciller de Milán, don Antonio Ronquillo, se encargase de leer la obra y valorar si su impresión era pertinente. ${ }^{12}$ Sin embargo, no fue la única persona a quien se le encargó la revisión del texto, ya que de manera paralela, en Madrid, se habían empezado las gestiones para tener más informes sobre los siete pliegos de los Comentarii sopra Cornelio Tacito. Uno de ellos se había confiado a don Pedro de Neyla, noble y religioso español, miembro del Consejo de Indias y caballero de la

11. "Que los siete pliegos que han venido acá se remitan a un ministro togado que los vea, y al marqués de la Fuente se le escriba que mantenga a este hombre asegurándole que V.M. le hará merced, como es justo que se le haga, porque estos escritos suelen hacer impresiones en los pueblos en gran perjuicio de los príncipes. Y que si quisiere pasar a Milán este Abad mande V.M. se le den quinientos ducados de ayuda de costa». Parecer del Consejo de Estado. Madrid, 5 de abril de 1644. AGS, SE, Legajo 3543-1.

12. Así se deduce de una carta del marqués de la Fuente escrita en Venecia, el 17 de septiembre de 1644. (AGS, SE, Legajo 3542-227): «En despacho de 13 de julio me manda decir V.M. que mantenga a fray Aurelio Bocalini, asegurándolo que le hará merced, que ha resuelto que el Gran Canciller de Milán vea el libro que desea estampar, y que si él quisiere pasar a aquel estado se le darán quinientos ducados de ayuda de costa. Luego le dije lo que V.M. había determinado y el agradecimiento que mostró el correspondiente a la ambición que ha manifestado de la gracia de V.M y al deseo con que vino de que se publique esta obra. Asegurome de nuevo el afecto con que continuaba en el servicio de V.M. y la estimación grande con que quedaba de todo lo que yo le decía, a que no solo se ajustó, pero volvió a suplicarme que si fuese gusto de V.M. quemar estos papeles lo haría sin dificultarlo.» 
orden de Calatrava, arzobispo de Palermo y obispo de Segovia (Matesanz del Barrio, 1995), quien no tardó en ofrecer su parecer. A finales de julio de 1644, Pedro de Neyla envió su opinión sobre los fragmentos del Lauretano a Pedro de Arce, secretario de la corte, haciendo referencia a la poca autoridad y reputación que solían tener los textos de Traiano Boccalini:

Muy poco debe de tener que hacer el marqués de la Fuente, pues hace plato para acá de pliegos del Boccalini como si fuera de algún autor de gran crédito. Yo he cumplido con lo que S.M me manda y remito a V.M. la consulta para que se sirva de encaminarlas. Dentro van los pliegos originales con los números y seńales que corresponden a lo consultado, con que sólo me queda que suplicar a V.M. se acuerde de mandarme en qué le sirva. Guarde Dios V.M. como deseo. En casa [sic], 30 de julio de 1644 .

Si los pliegos originales no pueden subir con la consulta como van dentro del pliego de S.M. puede V.M. servirse de abrirle y mandar que se copien y se les pongan a la margen los números y que se raye en cada uno lo que va rayado, con que irá como conviene para la inteligencia de lo consultado. Guarde Dios a V.M. como deseo. A 31 de julio de $1644 .{ }^{13}$

Junto con estos comentarios también remitió a la corte los siete pliegos que había valorado. Se trataba de los catorce primeros folios del libro tercero de los Comentarii bocalinianos, debidamente censurados. Siguiendo sus indicaciones, Pedro de Arce mandó que se copiaran de nuevo, se añadieran los números correspondientes al principio de cada apartado y se subrayaran los fragmentos que Pedro de Neyla había considerado oportuno eliminar. ${ }^{14}$ De esta manera, a mediados de octubre llegó el informe y el texto censurado a los miembros del Consejo de Estado. Reunidos el duque de Villahermosa, el marqués de Castañeda, el marqués de Valparaíso y el marqués de Loriana debatieron sobre el informe de Neyla:

Don Pedro de Neyla dice en la consulta que de ninguna manera tiene por conveniente que esta impresión se publique debajo del nombre de V.M. por las causas y razones que pondera, y que a su corto juicio no importará más que estas obras que trata de imprimir hoy el Abad fray Aurelio salgan a luz sin expurgarse que importó la estampa de las primeras, en que el autor dijo cuanto se le vino a la pluma, dictado de su malignidad y pasión, por cuya causa ninguno ha hecho concepto de lo que escribió, ni lo hará de los cuentos que metiere en sus Consideraciones políticas, por de autor desapasionado y bien informado de la verdad de las historias y sucesos. Y apunta don Pedro en la consulta referida los reparos que hace en los siete pliegos de Boccalini. ${ }^{15}$

13. Parecer de don Pedro de Neyla. 30 de Julio de 1644. AGS, SE, Legajo 3543-216.

14. El texto de los Comentarii censurados por Pedro de Neyla se puede consultar en AGS, SE, Legajo 2543-215.

15. Parecer del marqués de Castañeda en el Consejo de Estado. Madrid, 21 de octubre de 1644. AGS, SE, Legajo 3543-213. 
El duque de Villahermosa consideró que a pesar del poco crédito que podían tener las obras de Boccalini, no era conveniente que se imprimieran para evitar que se divulgaran infamias contra la monarquía. Apuntó que la obra debía ser revisada en su totalidad y sugirió el nombre de algunas personas a quienes se podía encargar esta labor, como el conde de la Roca o el mismo don Antonio Ronquillo:

El duque de Villahermosa dijo que habiendo visto lo que informa don Pedro de Neyla y escribe el marqués de la Fuente le parece que aunque este autor tenga poco crédito es de inconveniencia para lo venidero que imprima cosas que sean de poco crédito a los señores reyes antecesores de V.M. o que puedan ser de perjuicio a la corona, y así se deben estorbar por los medios convenientes y procurar que quede en la memoria en los hombres las acciones más acreditadas y justas que entiende. No conviene que el libro salga debajo la protección de V.M. ni se dedique, y que convendría se viese todo y examinase para quitar dél lo perjudicial y viniendo en esto su autor y reprimiéndole en lo que se le advirtiere se le podría dar alguna ayuda de costa, y si él quisiese irá a Milán. Se podría remitir al marqués de Velada para que algunas personas pláticas e inteligentes vieren todo el libro y consulten lo que pareciere, y si el conde de la Roca o don Antonio Ronquillo no hubiesen partido serían a propósito para que le viesen. Y si el autor le quisiese dar para que se viese acá se podría remitir a los mismos dos que apunta.

En el mismo sentido se pronunciaron el marqués de Castañeda y el marqués de Valparaíso, insistiendo en la necesidad de que la obra se enviara por completo para poder proceder a su correcta revisión. ${ }^{16}$ Por su parte, el marqués de Loriana solicitó también que se reconociera la amabilidad de fray Aurelio por no querer imprimir la obra sin que primero se juzgase su conveniencia, lo que demostraba que «ni aun indirectamente quiere hablar contra la monarquía de V.M., y esto corre con mayor fuerza por ser criado del rey de Polonia». ${ }^{17}$

16. «El marqués de Castañeda dijo que habiendo de consultar este consejo, como V.M. se sirve de mandarlo, el juicio que hace de lo escrito modernamente por el abad Boccalini dirigido a V.M., convendrá que primero se manifieste todo lo que ha escrito y que se vea en el Consejo porque si lo uno tiene semejanza con lo otro cortas gracias se le deberán, porque habla en materias inciertas contra el crédito y intención de tan grandes príncipes y tan católicos. [...] Y con esta consideración cree el Marqués que convendría se procediese con él con confianza y se le hiciese alguna merced procurando reducille que enviase todo lo escrito aquí, donde hay ministros de V.M. que con más largas noticias podrán comentar estos papeles de lo que lo podrán hacer en Italia, donde han de ser muy mendigadas las noticias y por ventura mal entendidas porque de españoles no tiene noticia el Marqués que haya sujetos a quien se pueda remitir este registro, habiendo, según se ha entendido, partido de allí el conde de la Roca y Gran Canciller, porque tienen su licencia. [...] El marqués de Valparaíso dijo que la carta del de la Fuente remitida a don Pedro de Neyla con los papeles que cita han obrado en echar de ver lo que se ha topado en siete pliegos, de que se infiere lo que habrá en todo lo demás de la obra, y así se conforma con el voto del marqués de Castañeda». Parecer del Consejo de Estado. Madrid, 21 de octubre de 1644. AGS, SE, Legajo 3543-213.

17. Ibid.

Studia Aurea, 8, 2014 


\subsection{La intervención de Antonio Ronquillo}

No tardaron en llegar a Venecia las instrucciones del Consejo de Estado, que indicaban con claridad al marqués de la Fuente que debía convencer a Aurelio Boccalini para que estuviese dispuesto a autorizar la revisión y corrección de todo el libro de los Comentarii. Esta labor fue encargada al Gran Canciller de Milán, don Antonio Ronquillo, por lo que se ofreció a fray Aurelio una ayuda de costa para su desplazamiento a Milán. ${ }^{18}$ A partir de ese momento se estableció una estrecha colaboración entre Antonio Ronquillo y el marqués de la Fuente para poder llevar a buen puerto el negocio de la impresión del libro y mantener sosegados los ánimos de fray Aurelio. De todo ello el Marqués iba dando debida cuenta a la corte española:

Por despachos de 26 de septiembre y 5 de octubre se sirve V.M. de mandarme decir que habiéndose reconocido la carta de Antonio Pérez en que decía a don Antonio Ronquillo su modo de entender sobre los libros de Boccalini, se le había ordenado que me enviase copia della, y que ajustásemos lo que nos pareciese, porque daría cuenta a V.M. pudiese resultar lo más conveniente. Y aunque en 17 de agosto remití copia de lo que habían escrito sobre esta materia a don Antonio (después de haber visto la carta deste religioso) espero a ver lo que me escribe de nuevo y procuraremos ajustar lo que más conviene a dar cuenta a V.M., porque pueda resolver lo que fuese servido. Y entretanto iré manteniendo al Boccalini, si bien es ardientísimo y necesitado, circunstancias que precisamente le hacen no solo inoportuno pero que dificulta el poder prometerme lo que yo deseo para el mayor servicio de V.M. ${ }^{19}$

En abril de 1645, Antonio Ronquillo ya había informado a la corte madrileña de su valoración sobre el texto del Lauretano, opinando que no convenía que la obra se publicara, ${ }^{20}$ un parecer que reforzaba el juicio inicial de don Pedro de Neyla y las posteriores aportaciones del Consejo de Estado. La situación era delicada ya que, a pesar de rechazar la impresión de la obra en España, era posible que alguna potencia enemiga de la casa de Austria decidiera sacarla a la luz. Así pues, y con el fin de evitar que un texto de tales características pudiera circular en letras

18. La triste situación económica del marqués de la Fuente provocó que se viese obligado a pedir a Espańa el envío de dinero para poder pagar el viaje de Aurelio: «Lo que no puedo dejar de representarle sin dilación es que el apuntamiento en los gastos secretos desta embajada será hacerle desesperar, pues si V.M. no se sirve de mandar desempeñarme y asistirme, no solo no podré satisfacer al Boccalini pero será fuerza que se me despidan los confidentes». Carta del marqués de la Fuente. Venecia, 23 de noviembre de 1644. AGS, SE, Legajo 3547-44.

19. Carta del marqués de la Fuente. Venecia, 23 de noviembre de 1644. AGS, SE, Legajo 3547-44. 20. Así lo atestiguaba el marqués de la Fuente en una carta a Felipe IV que fecha de 22 de abril de 1645. AGS, SE, Legajo 3545-184. Además, en esta misma carta, el Marqués contaba que había rechazado la propuesta que le había hecho Luigi Manzini para revisar el texto de los Comentarii: "Y después acá puedo añadir que no he admitido un ofrecimiento de este género que me hizo Luis Manzini porque si bien es hombre de ingenio grande, juzgo que no tiene toda la prudencia de que necesitan escritos desta calidad.» 
de molde por Europa, la estrategia pasó por conseguir el manuscrito original con el pretexto de incorporarlo a la biblioteca privada del Rey. Sin embargo, no tardaron los dirigentes españoles en darse cuenta de que tal y como había informado desde finales de 1643 el marqués de la Fuente, existían varias copias manuscritas del texto que estaban en posesión de la República de Venecia y del rey de Polonia. En esas circunstancias, la mejor táctica para evitar la publicación dela obra - $\mathrm{O}$ dilatarla todo lo posible - consistía en tener convencido a Aurelio Boccalini de que se estaba procediendo con la revisión de los Comentarii, mientras lo tenían entretenido con alguna ayuda económica para que no decidiera impulsar la publicación en otro lugar. Así lo acreditaba el marqués de la Fuente:

En carta de 29 de agosto se sirve V.M. de mandarme decir que habiendo copias de lo que dejó escrito Trajano Boccalini tendrá inconveniente pedir a su hijo el original para la librería de privada de V.M., que lo que conviene es irle entreteniendo y oírle con menos confianza de lo que me ha sucedido, pues me persuadía a que me entregaría el original sin quedar trasladado, y porque el gobernarme así sería faltar a la atención que debo y a la que tengo en cuanto toca al servicio de V.M., me parece satisfacer en primer lugar a esta parte trayendo a la memoria de V.M. que en el despacho de 13 de noviembre de 1643, en que di cuenta de lo que proponía el Boccalini, la di también de que le oía con recato (juzgando que era conveniencia propia suya y no afecto particular) de que había solicitado disuadirle del intento de estampar esta obra y de que había dos copias della fuera de su poder, con lo cual ni yo pude creer que me había engañado, pues me confesó que no era único este mano escrito, ni dar más particular noticia a V.M. para que resolviese lo que juzgase mayor servicio suyo. Con este mesmo recato he continuado el oírle, valiéndome solo de él en lo que no podía servirme de otro. ${ }^{21}$

\subsection{Otros países entran en juego: Francia, Polonia y Saboya}

Después de año y medio de negociaciones, a principios de 1645, el residente de la República de Venecia en Milán, Taddeo Vico, advirtió a la Serenísima que Aurelio había puesto varios volúmenes de los Comentarii de su padre a disposición del Gobernador español de Milán, Antonio Ronquillo, lo que supuso la inminente suspensión de la paga vitalicia que le había otorgado la República en 1627. No tardó Aurelio en lamentarse vanamente de su desdicha ante la corte de Polonia y ante el marqués de la Fuente, alegando que había perdido la paga porque había obedecido las órdenes de Ladislao IV (Gagliardi, 2013: 226). Sin ese sustento, una de las posibilidades para conseguir rendimientos económicos pasaba por imprimir la obra de su padre, por lo cual Aurelio no tardó en multiplicar los intentos de difundir los Comentarii. Parece que por esas fechas, y ante la dilación de las negociaciones con España, el hijo del Lauretano ya se había puesto en contacto con el tesorero del rey

21. Carta del marqués de la Fuente. Venecia, 4 de noviembre de 1645. AGS, SE, Legajo 3545-11. 
de Francia para ofrecerle los comentarios, ${ }^{22}$ e incluso hacía partícipe al marqués de la Fuente del interés que tenía cierto embajador francés en publicar la obra, un hecho que utilizaba también como herramienta de coacción para intentar acelerar la corrección de la obra. ${ }^{23}$ Así lo consideraba el Marqués:

Yo, con todo, estudio entretener al Boccalini como V.M. manda, si bien no es fácil, así por verse sin qué comer como por su ardiente condición. Estos días me ha dicho que el embajador de Francia, sabiendo que está en Milán esta obra para corregirla, trata de buscar alguna copia con que anticipar la estampa, que me lo avisaba por no perder más con los juicios que esto ocasionaría que lo que perderá siendo otro el que saque a luz estos escritos. Si es por apresurar la resolución déjolo al juicio de V.M., pues hasta ahora no he podido penetrar nada que apruebe o desmienta esta noticia. ${ }^{24}$

A principios de septiembre de 1646 Antonio Ronquillo escribía a Felipe IV insistiendo de nuevo en la necesidad de no publicar un texto lleno de infamias contra los reyes de España. Según su opinión, la solución no pasaba por eliminar estos pasajes sino por reescribir de nuevo toda la obra, y mientras se procedía a la reelaboración de la misma sugería dar alguna recompensa económica al hijo del Lauretano. ${ }^{25}$ Desde Madrid se instaba a la estrecha colaboración entre Antonio Ronquillo y el marqués de la Fuente para resolver los asuntos de Boccalini, aunque

22. «Esseguire i miei instantissimi pensieri d'esporre al mondo sotto aug.mo nome della M.tà Sua li scritti di mio padre sopra Cornelio Tacito. Confido che la lunghezza degli anni non avranno cancellati i fondamenti delle mie fortune, e che riceverò i soliti honori da V. S. Ill.ma cui bacio humilmente le mani». Citado por Tirri (1998: 474, n. 54) y Gagliardi (2013: 224-225).

23. En otra carta del marqués de la Fuente aparecen los argumentos que utilizaba Boccalini para desdeñar la publicación del texto en Francia: «despertó [Aurelio Boccalini] tal odio en los ministros de Francia que le quisieron beber la sangre, y ahora si se sacan a luz estos discursos políticos malogrará el deseo de servir a V.M. enmendándolos, perderá lo que le valiera si por su cuenta se vendiesen tantos cuerpos como se estamparan, y lo que se pudiera prometer de los tres primeros monarcas, a quien pensaba dedicar la primera, segunda y tercera parte.» Carta del marqués de la Fuente. Venecia, 4 de noviembre de 1645. AGS, SE, Legajo 3545-11.

24. Carta del marqués de la Fuente. Venecia, 4 de noviembre de 1645. AGS, SE, Legajo 3545-11. 25. «Sirvióse V.M. de mandarme reconociese las notaciones políticas del Boccalini sobre Cornelio Tácito y hallo que están llenas de malignidad contra las acciones del señor Rey don Felipe II y del señor Emperador don Carlos, y generalmente contra todos los espańoles. Si esto se quita, fáltale a la obra mucho de sazón, y aventúrase que en estampándola en aquella forma se haga sospechoso y obligue a otros que tienen también copias a que las estampen como están y aún con más veneno. Y solo pudiera salir a luz cuando con aquellos materiales se formara la obra de nuevo. El padre Boccalini insta por los libros y se queja de que por haberlos entregado le quitó la República la pensión que le daba, y se ha hecho difidente de Francia, y perdido sus comodidades, y como V.M. se sirviese de mandarle ir socorriendo de cuando en cuando con alguna cosa, se podría ir entreteniendo. Y en el entretanto creo se podría disponer que alguna persona pusiese la obra en estado que, quitando lo más perjudicial y dejando algunas cosas de menos inconviniente, la formase de manera que se pudiese publicar. V.M. mandará lo que fuere de su real servicio». Carta de don Antonio Ronquillo a Felipe IV. San Pedro de Arenas, 3 de septiembre de 1646. AGS, SE, 3851, fol. 78 r-v. Cito por Gagliardi (2013: 229). 
las opiniones de los representantes españoles en Italia distaban de ser unánimes. En una epístola de principios de 1648, el Marqués insistía en el peligro que podía suponer la desesperación de Aurelio Boccalini, que podría propiciar la aparición del texto en otra corte europea, teniendo en cuenta la cantidad de copias de los Comentarii que circulaban:

Dije que esperaría respuesta de don Antonio Ronquillo por si nos ajustábamos por decir a V.M. lo que teníamos por conveniente a su servicio, y aunque entrambos le deseamos sin diferencia, por ventura nos divide en el modo de servir el haber él leído los escritos que [yo] no he visto. Y el no haber oído don Antonio al Boccalini, ni comprehende el peligro que o desesperándose él los estampe, o queriendo franceses que se publiquen los impriman, o bien que secretamente el mismo Boccalini se valga para que salgan a luz de algún parcial de la corona de Francia por conseguir lo que tanto desea y al mismo tiempo el no disgustar a V.M. ${ }^{26}$

La impresión del texto bajo la protección de la corona de Francia u otra potencia europea causaría graves inconvenientes a España por lo que el Marqués consideraba que lo principal era convencer a Aurelio de no publicar el texto y asegurase de que tampoco lo imprimiría en ninguna otra parte. En esta ocasión, el encargado de ganarse la confianza del hijo del Lauretano fue Antonio Ronquillo, quien tenía que irle entreteniendo para que se encontrara a gusto mientras transcurría el tiempo y la obra no se publicaba. De manera paralela, el Marqués había instado a fray Aurelio para que pidiese algún favor al rey de Polonia en compensación por la paga vitalicia que le había suprimido la República de Venecia, como por ejemplo, ser nombrado internuncio en Nápoles.

Estas y otras consideraciones [...] me obligan a juzgar que V.M. podría enviar a don Antonio orden condicional para que si pudiese divertir al Boccalini de que sacase a luz estos papeles y asegurarse de que por otra parte no saldrían, lo hiciese a cualquier precio, que cualquiera merecerá según los grandes inconvenientes que supone en la obra. Pero que en caso de no poder reducirle a esto, abrazase el partido de corregirla y acrecentarla y que según la forma en que lo dispusiese tomase el punto para lo que se había de dar de contado por recompensa de la pensión que le ha suspendido la República estos últimos cuatro ańos, y que atendiendo a lo mismo que consiguiese, le señalase lo que V.M. fuere servido de mandarle dar cada año, siendo cierto que si sepulta en el silencio estos papeles merecerá mayor demostración del real ánimo de V.M. con que no se puede tomar regla segura hasta ver lo que es posible vencer con este hombre. Y por esta consideración (si bien lo que me estrechaba) me obligó a decirle lo que V.M. le había hecho merced reserve la cantidad.

Teniendo don Antonio orden de este género podrá o conseguir el primer intento o irse valiendo de la misma corrección para servirse del beneficio del tiempo y esperando los accidentes que pudiesen facilitar el no perfeccionar jamás [la] estampa,

26. Carta del marqués de la Fuente. Venecia, 8 de febrero de 1648. AGS, SE, Legajo 2547-77. 
pues mientras él viere que se trata con efecto no pensará otros medios. Lo que puedo asegurar a V.M. es que en una o en otra forma es preciso que se tome esta última resolución, porque ya no hay medios términos con que entretener más al Boccalini, pudiendo durar poco el partido con que ahora le tengo más templado, habiéndole propuesto que sería bien pretender que su amo le nombrara por internuncio en Nápoles, añadiendo que por los medios que yo pudiere lo esforzaré y deseándolo él infinito, le tendremos más a la mano mientras le durare esta esperanza. Y con efecto haríamos dél lo que quisiésemos si su amo le eligiese. Yo procuraré por todos los caminos mantenerle mientras toma resolución. ${ }^{27}$

A mediados de mayo de 1648 el Marqués seguía sin tener resolución de la corte, por lo que escribió de nuevo a Madrid insistiendo en la necesidad de saber cuáles eran las instrucciones y en lo difícil que estaba siendo quietar los ánimos de Aurelio: «Sólo diré ahora que cada día es más precisa la resolución, que sin tenerla de V.M. no podemos adelantar más la materia, y que él está cada día más impaciente. Voyle sobrellevando todavía con la esperanza de que podría ir por internuncio a Nápoles. $»^{28}$ Asimismo, en una de sus diferentes misivas a la corte de Madrid, el Marqués se tomó la libertad de proponer un nuevo revisor para los Comentarii. En esta ocasión, se trataba de un escritor italiano muy próximo a la corte madrileña que conocía a la perfección la obra de Tácito: «En caso de que no quiera desistir de sacar a luz esta obra, de que se sirve V.M. de ordenar que el marqués Virgilio Malvezzi vea, corrija, y apruebe todos papeles, pues por buen criado de V.M., por inteligente y por poco ocupado será mejor que nadie, perfeccionar la [obra] y añadir lo que juzgare que conviene a V.M.» (9 $^{29}$ Según el Marqués, Virgilio Malvezzi, el autor de los Discorsi sopra Cornelio Tacito, que se habían publicado en Venecia el 1622, y el cronista oficial de Felipe IV, era el candidato más adecuado para la correcta revisión de los Comentarii boccalinianos. No hay duda de que los conocimientos que tenía Malvezzi de la obra de Tácito así como su depurado estilo literario le convertían en un buen corrector o refundidor de la obra, pero desconocemos si esta propuesta recibió la aprobación del Consejo de Estado y si efectivamente, el autor de Il Rómulo inició la tarea de revisión del texto del Lauretano.

Por su parte, Aurelio Boccalini, como ya había venido haciendo desde finales de la década de los Treinta, siguió carteándose con los principales representantes europeos para intentar vender la herencia intelectual de su padre, algo que no pasaba inadvertido por el Consejo de Estado español..$^{30}$ Así, a principios de enero

27. Ibid. El Consejo de Estado vio esta carta el 14 de abril de 1648. AGS, SE, Legajo 3547-66.

28. Carta del marqués de la Fuente. Venecia, 16 de mayo de 1648. AGS, SE, Legajo 3547-133.

29. Ibid. El Consejo de Estado vio la carta del marqués de la Fuente el 16 de julio de 1648. AGS, SE, Legajo 3547-129.

30. «Discurre también en el tiempo que este fraile hacía capital de este libro y que a cada príncipe de Italia y aun de la Europa procura venderle la parte que le puede tocar.» Parecer del Consejo de Estado. Madrid, 16 de julio de 1645. AGS, SE, Legajo 3850-50. 
de 1649 había indicios de que el rey de Polonia —que como recordaremos tenía un manuscrito de la obra, obsequio del mismo fray Aurelio- deseaba poner el texto en letras de molde. Así daba cuenta de la cuestión el marqués de la Fuente a Felipe IV:

Después de lo que en 20 del pasado escribí a S.M. en orden a los intereses de fray Aurelio Boccalini, recibió una carta del secretario Fantoni (que originalmente vi) en que le decía que aquel Rey deseaba que saliesen a luz las obras de su padre, dándole lo que hubiese menester para la estampa, y añadía que con este pretexto sería bien que llegase a Varsovia, adonde podría en persona ajustar sus intereses. Esta novedad le hizo tal fuerza que apretándome a que de contado le diese los tres mil ducados de ayuda de costa y el despacho situándole la pensión, y no pudiendo yo satisfacerle a ninguna de las dos cosas, me vi en gran embarazo para reducirle a que mantuviese lo que me había ofrecido. Y últimamente le escribí un papel en la forma que me pareció que más podría facilitar mi intento, al cual me respondió lo que V.M. verá por la copia inclusa, que se la remito, porque vea las pérdidas que representa y cómo me ha entregado todos cuantos papeles tenía. Héselo agradecido empeñándome en asegurarle que en cinco meses tendría con efecto cobrados los tres mil ducados y orden donde se le había de pagar la pensión. Desea que se le señale o en algún obispado de los de Italia o algún beneficio de la misma cantidad. ${ }^{31}$

Ante lo que parecía la inminente oferta de publicación de los Comentarii en la corte de Polonia, el marqués de la Fuente se vio en la obligación de ceder a las reclamaciones de fray Aurelio, aceptando darle 3.000 ducados de ayuda de costa y una pensión, que fue fijada en 800 ducados anuales. Sin embargo, dada la precaria situación económica del Marqués, el pago del sueldo correspondiente no fue inmediato, sino que se le adelantó una parte a fray Aurelio y la otra se pidió a Madrid. En septiembre de este mismo año Boccalini sólo había cobrado 1.000 ducados de los 3.000 que se le habían ofrecido de ayuda de costa y todavía estaba a la espera de que se le asignase oficialmente la pensión anual..$^{32}$ Durante esos meses, la principal ocupación del Marqués fue la de convencer a fray Aurelio de la pronta llegada de la ayuda de costa que le había prometido, a la vez que intentaba gestionarle la obtención de algún puesto eclesiástico en Italia, para lo cual tenía que solicitar de nuevo el favor de Felipe IV:

Mandase escribir al embajador de Roma que le procure algún título o de Abadía o de Obispado in partibus que es en lo que funda el estar con decencia y hábil para poder acudir a lo que ahí o en Nápoles quisieren mandarle los ministros de V.M.

31. Carta del marqués de la Fuente. Venecia, 13 de enero de 1649. AGS, SE, Legajo 3548-76.

32. Véase la carta del marqués de la Fuente. Venecia, 25 de septiembre de 1649. AGS, SE, Legajo 3548-178: «Vuelvo de nuevo a referir a V.M. lo que ha pasado y los términos que tiene la materia porque pueda ordenar que se le señale la pensión y se le den los 2.000 ducados que se le deben de la ayuda de costa, habiéndole ya dado mil.» La resolución del Consejo de Estado de 24 de diciembre de 1649 dictó que se cumpliera con lo prometido. AGS, SE, Legajo 3548-177. 
Y pareciéndome que serviría de molestia le procuré disuadir del viaje, como lo he conseguido, asegurándole que lo que V.M. había resuelto que se le diese sería pronto $[. .$.$] , favor que juzgo le tiene merecido porque efectivamente con privarse de la$ estampa ha perdido dos mil escudos, que me consta le daba un estampador, lo que tenía de la República y lo que le valdrían las dedicatorias. ${ }^{33}$

Por otra parte, las habilidades diplomáticas del marqués de la Fuente se centraron también en evitar la publicación del texto del Lauretano en la corte de Ladislao IV, por lo que en esta ocasión recurrió a la ayuda del cardenal Gil Carrillo de Albornoz:

He podido entender que los padres jesuitas hacen en Polonia grande esfuerzo a la Reina, sospecho que solicitados de franceses, para que se estampe valiéndose de una copia que tenía el Rey. Y aunque he avisado al cardenal Albornoz porque pueda disponer con el que hoy gobierna la religión lo que sabrá encaminar la prudencia, me ha parecido dar cuenta a V.M. porque pueda mandar disponer desde ahí lo que juzgare conveniente a este fin. ${ }^{34}$

Cansado de la dilación de las resoluciones de la corte española, y suponemos que desconfiando también de las promesas del marqués de la Fuente, a finales de los años cuarenta, Aurelio Boccalini volvió a diversificar sus intentos de publicación de la obra. Aparte de las opciones españolas — que eran más bien exiguas_-, en 1649 que estaba barajando otras posibles salidas editoriales para los comentarios paternos. Por un lado, sabemos que la obra se quería imprimir en Polonia, donde los jesuitas tenían la intención de sacar a la luz un impreso a partir del manuscrito que estaba en poder del Rey. En marzo de ese año, el mismo Boccalini se había puesto en contacto con la duquesa regente de Saboya, Cristina de Francia, a quien también le había mandado un ejemplar manuscrito de los Comentarii para su publicación. ${ }^{35}$ E incluso, en sus arduas negociaciones con el marqués de la Fuente, fray Aurelio había insinuado que la República de Venecia le había ofrecido el restablecimiento de su pensión vitalicia a cambio de publicar la obra al gusto de la Serenísima. ${ }^{36}$

33. Carta del marqués de la Fuente. Venecia, 24 de abril de 1649. AGS, SE, Legajo 3548-110.

34. Carta del marqués de la Fuente. Venecia, 28 de agosto de 1649. AGS, SE, Legajo 3548-150. La carta se vio en el Consejo de Estado del día 6 de noviembre de 1649 y se resolvió: «El Consejo que se le diga que V.M. queda advertido de todo y que si saliere la estampa en Polonia envíe un cuerpo». AGS, SE, Legajo 3548-149.

35. «Gradisca Vostra Altezza Reale questa mia umilissima oblazione; che se io poi conseguirò il mio Desiderio di poner sotto il torchio questi volumi, gli vederà il Mondo tutti aspersi delle Glorie di Cotesta Real Casa, e dio mi preggerò di adornare buona parte dell' Augustissimo Nome di Vostra Altezza Reale, da cui attenderò d'udire in tanto i sensi, acciò che gradendo le l'esibizione possa incontanente commandarne le copie.» Citado en Tirri (1998: 468, n. 42) y Gagliardi (2013: 226-227).

36. «Sobreviniendo el enviar el rey de Polonia despachos suyos a la República por otra mano, y con esto darse él por despedido aumentó el esfuerzo para que con efecto se le diese con qué vivir 
Desconocemos el alcance de estos negocios — no hace falta decir que ninguno de ellos llegó a buen puerto-, pero lo cierto es que a principios de marzo de 1649 Aurelio Boccalini escribía directamente a Felipe IV haciéndole partícipe del interés que tenían varios dirigentes europeos por las obras de su padre, entre los cuales mencionaba la duquesa de Saboya y el rey de Polonia. En esta misma misiva, describía también el grave perjuicio económico que le suponía publicar la obra bajo el auspicio de España, lo que equivalía a la pérdida de los cuatrocientos ducados que le había concedido la República de Venecia y de una pensión de trescientos escudos que le pagaba la potencia de Francia, una manera no muy sutil de solicitar cierta compensación por las pérdidas sufridas:

Potendo colla stampa ritrarre utili grandissimi, maggior emolumento potevo promettermi dal dedicarla partitamente a' vari potentati, che per loro gravi interessi ne sospirano la publicatione, e dall'emolumento ne sarebbe derivata a mio vantaggio la protettione, l'assistenza, l'honore; l'animo mio, però, non si lasciò giammai dominare da così interessate considerationi. Ė inevitabile il rischio a cui mespongo di tradir le promesse che feci già sono alcuni mesi a Madama di Savoia, la quale, con affettuosa instanza, mi richiese una copia di queste fatiche. Questa replica confermarà certamente la sua indignatione e mi privarà affatto della pensione di quattrocento ducati che mi sospese già quattr'anni sono, quando per ubbidire agl'ordini benignissimi di sua Maestà Cattolica mi portai a Milano per consegnare, come feci, al sig. don Ronchillo questi scritti paterni. Può anco questa mia deliberatione veder di me mal sodisfatta la maestà del Re di Polonia, alla cui real persona e casa ho l'onore d'aver fedelmente servito da dieci anni continui, disponendo liberamente di queste opere, i cui originali trovandosi appresso la Maestà sua, mi ha fatto assicurare per il secretario Fantoni ch'in lui continua l'intentione del gloriosissimno Re di farle pubblicare alle stampe a proprie spese. Perdo coll'hereditaria protestatione della Francia una pensione di trecento scudi, che dalla regia liberalità mi fu assegnata già venti quattr'anni sono, e finalmente, s'è vero com’è verissimo, che sopravvivono i defonti [?] nella fama de i scritti loro, vorrà forse tal uno che mi sia dimenticato del nome di figlio e m'accusarà che nel sopprimere parti sì rare habbia due volte empiamente sotterrato il genitore, e pure a tutti questi rispetti ha prevaluto la forza della mia interna e costante veneratione e la stima che da me è stata fatta d'acquistarmi col favore di V.E. ${ }^{37}$

No tenemos más noticias de las vicisitudes del texto de los Comentarii hasta 1652, cuando el marqués de la Fuente se dirigió al Consejo de Estado para informar de la muerte por enfermedad de Aurelio Boccalini, y por consiguiente, el final de la negociación por la impresión de la obra del Lauretano. A Aurelio Boccalini le sobrevino la muerte sin haber recibido todavía los 3.000 ducados

o que sino estamparía sus obras como la República gustase, que era el medio con que le habían ofrecido restituirle la pensión y los caídos». Carta del marqués de la Fuente. Venecia, 20 de febrero de 1649. AGS, SE, Legajo 3548-74.

37. Carta de Aurelio Boccalini a Felipe IV. 6 de marzo de 1649. AGS, SE, Legajo 3548-77. 
de ayuda de costa que se le prometieron en 1649, una cuantía económica que el Marqués siguió reclamando a Madrid para pagar las diversas deudas que había dejado el hijo del Lauretano. Por otra parte, y siguiendo las órdenes reales, el Marqués afirmaba estar recopilando todos los documentos relativos a las obras de Traiano Boccalini para remitirlos a la corte española. En este sentido, el duque del Infantado, don Rodrigo Gómez de Sandoval y Mendoza, que fue embajador en Roma, gobernador de Milán y virrey de Sicilia, le había comunicado que sabía de la existencia de algunos cuadernos más de anotaciones boccalinianas, supuestamente conservados en casa del cuñado de fray Aurelio, es decir, en casa del marido de su hermana Caterina, Marcello Giustiniani:

\begin{abstract}
En despacho de 23 de enero me manda V.M. decir lo que había resuelto porque se diese satisfacción a fray Aurelio Boccalini, y me ordena que remita los manuscritos de su padre que me entregó. A lo primero puedo decir que él es muerto después de haber padecido una larga enfermedad, con que no tendrá lugar la ejecución de las órdenes de V.M., a quien me parece representar que será acto muy propio de su piedad el enviar orden para que la parte de ayuda de costa que falta de lo que yo le di se desembolse a su heredero, si es que le ha dejado, que hasta ahora no lo sé, o por lo menos lo que bastare para pagar las deudas, que no excedieren de la cantidad, bien que me consta que dejó muchas. En cuanto a los papeles ejecutaré lo que V.M. me manda y para que se puedan disponer con más claridad, habiéndome el Duque del Infantado escrito que en poder de un cuñado de fray Aurelio había algunos cuadernos, solicitaré unirlos con estos otros por si pudiese perfeccionarlos, pues si bien son seis u ocho cuerpos en folio los que he podido componer, a algunos de los libros les falta el principio, en otros no se continúa el discurso y en parte dellos queda imperfecto. En recibiendo los que espero que me enviará el Duque, procuraré ajustarlos lo mejor que se pudiere y gozaré de la primera ocasión segura para remitirlos como me ordena V.M. ${ }^{38}$
\end{abstract}

\title{
3. La publicación de los Comentarii
}

A pesar de los numerosos intentos de Aurelio Boccalini para sacar en letras de molde los Comentarii sopra Cornelio Tacito de su padre, el último heredero del Lauretano falleció a principios de 1652 sin ver publicado el texto. Dejaba a sus espaldas veinticinco ańos de largas negociaciones y vanas estrategias para conseguir publicar el legado literario de Traiano Boccalini y con ello obtener algún beneficio económico. Desde los primeros intentos junto a su hermano Rodolfo de imprimir la obra en la República de Venecia, hasta las últimas tentativas en la corte francesa y en el ducado de Saboya pasaron cerca de veinte años. Un dilatado período que se vería complementado con otros veinticinco años hasta que finalmente el texto apareció en letras de molde. Durante este tiempo de circula-

38. Carta del marqués de la Fuente. Venecia, 16 de marzo de 1652. AGS, SE, Legajo 3551-77. El Consejo de Estado vio la carta del marqués de la Fuente el 28 de mayo de 1652. AGS, SE, Legajo 3551-67. 
ción manuscrita, proliferaron las copias y las versiones de la obra del Lauretano, siendo en varias ocasiones objeto de censuras, refundiciones y reelaboraciones. ${ }^{39}$

A finales de la década de los Setenta, sesenta y cuatro años después de la muerte de Traiano Boccalini, aparecieron las dos primeras ediciones del texto. ${ }^{40}$ La princeps se publicó en 1677 bajo el título I Comentarii di Traiano Boccalini romano sopra Cornelio Tacito, impresa por Giovanni Battista della Piazza en Cosmopoli, que algunos investigadores han identificado con la localidad de Ámsterdam, poniendo de manifiesto el interés que suscitaban las obras de Boccalini en los impresores flamencos. Asimismo, la identidad del impresor parece que tampoco sería la indicada y las hipótesis más recientes apuntan a que podría tratarse de Pieter Bleau (Hendrix, 1995; Tirri 1998: 464-465; Salmaso 2011:617). Un año después, en 1678 aparecía la segunda edición de la obra formando parte de un compendio de obras de Traiano Boccalini. El título rezaba La Bilancia politica di tutte le opera di Traiano Boccalini. En esta ocasión, el antígrafo de los Comentarii era el de la edición de 1677 e iba acompañado de varias anotaciones en clave protestante del intelectual flamenco Ludovico du May. El texto lo imprimió Giovanni Hermano Widerhold, en la localidad de Castellana, es decir Châtelaine, un pequeño pueblo cerca de Ginebra (Tirri, 1998: 446).

Assunta Tirri, en su excelente artículo sobre la aproximación a los materiales para la edición de los Comentarii de Boccalini, ya indicó la posible procedencia italiana de los manuscritos que sirvieron para la edición de 1677. Sin embargo, y a la luz de los nuevos documentos encontrados en el Archivo General de Simancas, parece que sería interesante comparar el texto de la princeps con los pliegos manuscritos que se enviaron a la corte española en 1643 y que fueron censurados por Pedro de Neyla. Un elemental cotejo por loci de ambos testimonios parece ponernos sobre la pista de la posible relación entre la censura de Neyla y las impresiones de finales de la década de los Setenta. La complejidad de la transmisión textual de los Comentarii boccalinianos y el poco espacio del que dispongo a estas alturas hacen imposible explicar adecuadamente esta interesante hipótesis de trabajo, a la cual sin duda intentaré aproximarme en algún análisis posterior.

39. Ardua será la labor del filólogo para elaborar una buena edición crítica de esta obra, una tarea a la que hace algún tiempo se han aventurado con valentía algunos italianistas. Véase el trabajo ya citado de Tirri (1998) así como los estudios de Baldassarri y Salmaso (Boccalini, 2006) y Salmaso (2011). 40. A pesar de que algunos biógrafos citan ediciones de 1667 y 1669 , la primera que he podido documentar se imprimió el 1677. 


\section{Bibliografía}

BaYle, Pierre, Dictionaire historique et critique, Rotterdam, Reinier Leers, 1697. Benzoni, Guido, Dizionario Biografico degli italiani, Roma, Istituto della Enciclopedia Italiana, 1969.

Boccalini, Traiano, Traiano Boccalini, introducción a cura de G. Baldassarri con la colaboración de V. Salmaso, Collana "Centolibri per milleanni», Roma, Istituto Poligrafico e Zecca dello Stato, 2006.

Bouza Álvarez, Fernando J., El libro y el cetro: la Biblioteca de Felipe IV en la Torre Alta del Alcázar de Madrid, Salamanca, Instituto del Libro y de la Lectura, 2005.

Cicogna, Emanuele Antonio, Delle inscrizioni veneziane, Venezia, Cicotti, 6 vols, 1824-1853.

GAGLIARDI, Donatella, «De autocensuras y censuras: el accidentado camino a la imprenta de los Comentarii sopra Cornelio Tacito de Boccalini (con un parecer del Consejo de Estado español)», en Las razones del censor. Control ideológico y censura en los libros de la primera edad moderna, Cesc Esteve (coord.), 2013, 217-237.

Hendrix, Harald, Traiano Boccalini fraerudizione e polemica: ricerche sulla fortuna e bibliografia critica, Firenze, Leo S. Olschki, 1995.

Matesanz del Barrio, José, «La colección de arte de don Pedro de Neyla, Obispo de Segovia (1644-1647)», Boletín del Seminario de Estudios de Arte y Arqueología: BSAA, Tomo 61, 1995, 433-452.

Tirri, Assunta, «Materiali per un'edizione critica delle Osservazioni a Cornelio Tacito di Traiano Boccalini», Il pensiero politico, 3 (1998) 455-485.

Salmaso, Valentina, "Traiano Boccalini e i Commentari a Tacito», Come leggere $i$ classici. Presenza e influenza dei classici nella modernità. Atti del Convegno internazionale di Napoli, 26-29 ottobre 2009, Roma, Salerno Editrice (Pubblicazioni del «Centro Pio Rajna». Sezione Prima, Studi e saggi 19), 2011, 609-624. 
